\title{
Annual and spatial variability of the beginning of growing season in Europe in relation to air temperature changes
}

\author{
Frank-M. Chmielewski*, Thomas Rötzer
}

\begin{abstract}
Humboldt University Berlin, Faculty of Agriculture and Horticulture, Institute of Crop Sciences, Subdivision of Agricultural Meteorology, Albrecht-Thaer-Weg 5, 14195 Berlin, Germany
\end{abstract}

\begin{abstract}
To investigate the annual and spatial variability in the beginning of growing season across Europe, phenological data of the International Phenological Gardens for the period 1969-1998 were used. The beginning of growing season (BGS) was defined as an average leaf unfolding index of 4 tree species (Betula pubescens, Prunus avium, Sorbus aucuparia and Ribes alpinum). The study shows significant changes in the mean air temperatures from February to April and in the average BGS in Europe since 1989. In the last decade the mean temperature in early spring increased by $0.8^{\circ} \mathrm{C}$. As a result the average BGS advanced by $8 \mathrm{~d}$. Between 1989 and 1998, 8 out of 10 years tend towards an earlier onset of spring. The earliest date was observed in 1990. The relationships between air temperature and the beginning of growing season across Europe were investigated by canonical correlation analysis (CCA). The spatial variability of both fields can be described by 3 pairs of CCA patterns. The first pattern, which explains most of the variance, shows a uniform structure with above (below) normal temperatures in whole Europe and consequently an advanced (delayed) beginning of growing season. The other 2 patterns show regional differences in the anomaly fields. Whereas the second CCA pattern has a meridional structure, the third pattern shows a zonal distribution. In all cases the anomalies of the regional air temperature and of the beginning of growing season correspond very well. The correlation coefficients between the anomaly fields range between 0.90 and 0.66. For all patterns appropriate examples in the observed data were found.
\end{abstract}

KEY WORDS: Phenology · Growing season · Climate change · Air temperature · Canonical correlation analysis

\section{INTRODUCTION}

The annual timing of spring events (budding, leafing, flowering) is mainly driven by temperatures after the dormancy is released. In many studies a good correlation between spring phases and air temperature was found (Fitter et al. 1995, Walkovszky 1998, Wielgolaski 1999, Sparks et al. 2000). Therefore phenological observations are among the most sensitive data for climate impact studies on vegetation at midlatitudes.

One of the most striking events in spring is the first appearance of foliage, generally called the 'green

*E-mail: chmielew@agrar.hu-berlin.de wave'. This conspicuous event is well visible in satellite images such as that for the normalized difference vegetation index (NDVI) and can be used to calibrate remotely sensed data (Schwartz 1999, Schwartz \& Reed 1999, Chen et al. 2000). In the last few years more and more papers have reported changes in the timing of phenological events (Braslavská \& Kamensky 1999, Beaubien \& Freeland 2000, Menzel 2000).

For Europe a correlation coefficient between the mean air temperature from February to April and the average beginning of the growing season (BGS) of -0.83 was found; an increase in the mean annual air temperature in early spring (February to April) of $1^{\circ} \mathrm{C}$ thus corresponds to an advance in leafing by approximately 7 d (Chmielewski \& Rötzer 2001). 
The aim of this study was to investigate the annual and spatial variability in the BGS between 1969 and 1998.

\section{DATA AND METHODS}

2.1. Phenological data. The International Phenological Gardens (IPGs) are a special phenological network in Europe founded by F. Schnelle and E. Volkert in 1957 (Chmielewski 1996). At present the network is coordinated by the Humboldt University Berlin, Institute of Crop Sciences (www.agrar.hu-berlin.de/ pflanzenbau/agrarmet/ipg.html). The idea of this network is to obtain comparable phenological data across Europe (beginning of leaf unfolding, flowering, autumn colouring, leaf fall, etc.) from plants which are not influenced by different genetic conditions. For this reason vegetative propagated species of trees and shrubs were planted at different sites in Europe (Fig. 1). In 1959 the first IPG started its phenological observations. Today about 50 IPGs across Europe record phenological data from 23 plant species. The network covers a large area in Europe from to 42 to $69^{\circ} \mathrm{N}$ and from $10^{\circ} \mathrm{W}$ to $27^{\circ} \mathrm{E}$.

For this study the leafing dates of 4 species (Betula pubescens, Prunus avium, Sorbus aucuparia and Ribes alpinum) were combined in an annual leaf unfolding index to define BGS. This annual mean of the leafing dates for the 4 selected species was calculated for each IPG over the period 1969-1998. In this paper the annual deviations from the long-term average were used exclusively. They were interpolated using a geographical information system (ArcView) to study the spatial structure of the BGS across Europe (see Fig. 3). Because of the very low density of IPGs in SW Europe (Italy, France, Spain, Portugal) the results for this area should be interpreted cautiously.

2.2. Climatic data. In order to investigate the annual variability of the BGS in relation to air temperature, gridded $2 \mathrm{~m}$ temperatures (NCEP/NCAR reanalysis data, Kalnay et al. 1996) for the period 1969-1998 were used. The NCEP/NCAR reanalysis uses a fixed stateof-the-art global data assimilation system and a database that is as complete as possible. The database has been enhanced with many sources of observations not available in real time for operations. Output variables are classified into 4 classes (A to D), depending on the degree to which they are influenced by the observations and/or the model. Class A indicates that the variable is strongly influenced by observed data, class B indicates that observational data and the model influence the variable and class $C$ indicates that the data are solely derived from the model. Data in class D represent a field that is fixed from climatological values. The $2 \mathrm{~m}$ air temperature we used is classified in class

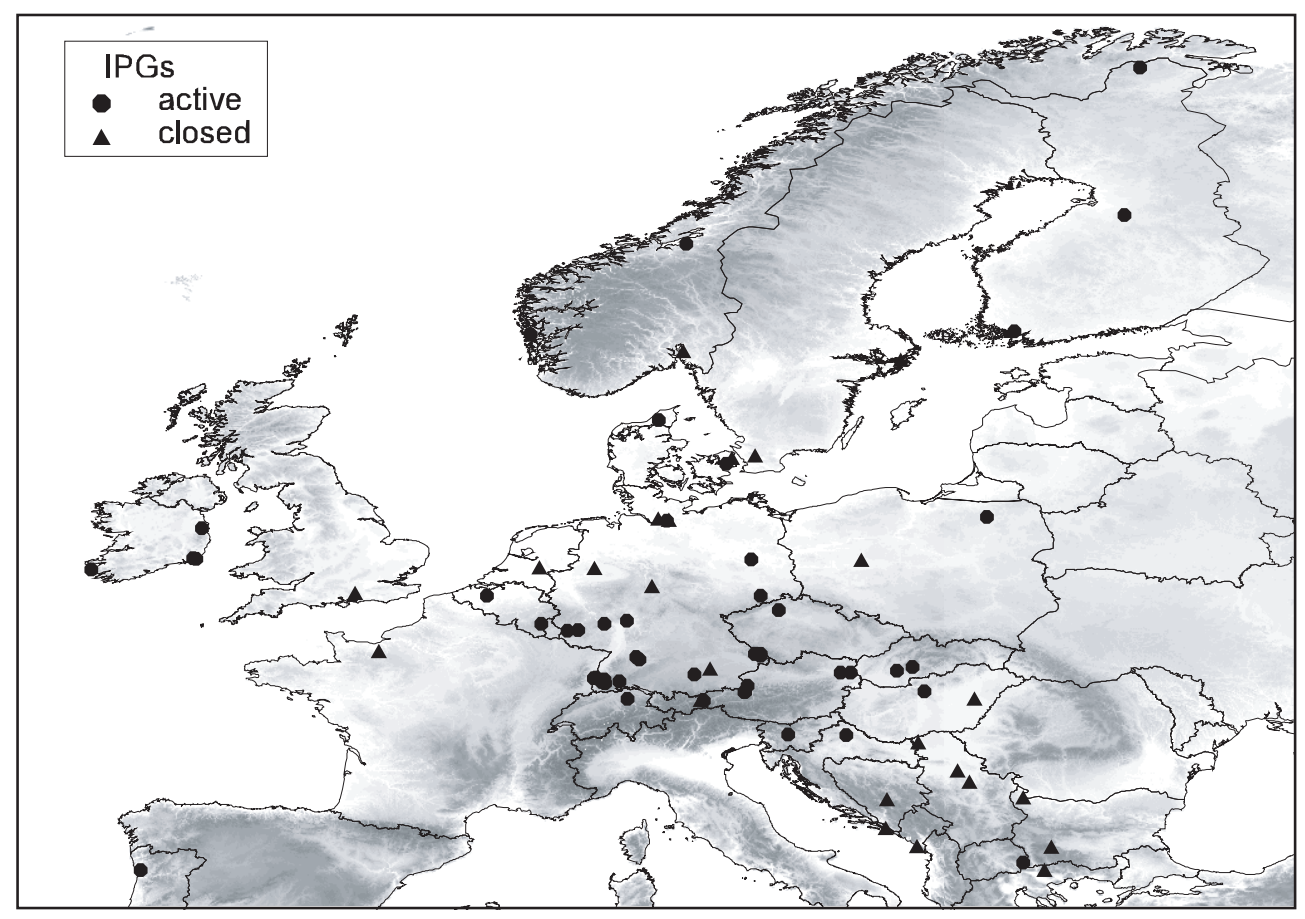

Fig. 1. Locations of the International Phenological Gardens in Europe. Active and already closed stations with observations for more than 10 years are shown 
B. In this study the mean air temperature from February to April (T24) was used. The horizontal resolution of the grid-point data is about $210 \mathrm{~km}$. They cover a region extending from 40 to $70^{\circ} \mathrm{N}$ and from $10^{\circ} \mathrm{W}$ to $25^{\circ} \mathrm{E}$. Thus, the climatic and phenological data have nearly the same geographical dimensions.

2.3. Method. Canonical correlation analysis (CCA) can be used to investigate the relationships between 2 multidimensional data sets. The statistical procedure was proposed by Hotelling (1936).

In this study the method was used to investigate the relationships between the anomaly fields of mean air temperature from February to April (T24; 340 grid points across Europe) and the BGS at 52 IPG stations. Before calculating the CCA, the 2 anomaly fields of T24 and BGS were approximated by the first 3 empirical orthogonal functions (EOFs) (Maak \& von Storch 1997), which explain most of the variance in the 2 fields. The other EOF patterns were disregarded.

CCA is well described in Manly (1986) as well as for climate research aspects in von Storch \& Navarra (1995): If $T_{j}(j=1,2,3)$ are the 3 leading EOFs of the air temperature anomaly field and $P_{j}(j=1,2,3)$ are the 3 leading EOFs of the anomaly field in BGS, then the CCA calculates a set of linear combinations of $T_{1}, T_{2}$, $T_{3}$, say

$$
U_{i}=a_{i 1} T_{1}+a_{i 2} T_{2}+a_{i 3} T_{3}, i=1,2,3
$$

and a set of linear combinations of $P_{1}, P_{2}, P_{3}$, say

$$
V_{i}=a_{i 1} P_{1}+a_{i 2} P_{2}+a_{i 3} P_{3}, i=1,2,3
$$

where the correlation between $U_{i}$ and $V_{i}$ is as large as possible. This means the correlation between $U_{1}$ and $V_{1}$ is a maximum; the correlation between $U_{2}$ and $V_{2}$ is a maximum, subject to these variables being uncorrelated with $U_{1}$ and $V_{1}$; and the correlation between $U_{3}$ and $V_{3}$ is a maximum, subject to these variables being uncorrelated with $U_{1}, V_{1}$ and $U_{2}, V_{2}$. Each of the pairs of canonical variables, $\left(U_{1}, V_{1}\right),\left(U_{2}, V_{2}\right)$ and $\left(U_{3}, V_{3}\right)$, represents an independent 'dimension' in the relationship between the 2 sets of variables $\left(T_{1}, T_{2}, T_{3}\right)$ and $\left(P_{1}\right.$, $\left.P_{2}, P_{3}\right)$. The first pair $\left(U_{1}, V_{1}\right)$ has the highest possible correlation and is therefore the most important, the second pair $\left(U_{2}, V_{2}\right)$ has the second highest correlation and is therefore the second most important, etc. The CCA patterns which belong to the canonical pairs are presented in Fig. 4. A parameter to measure the 'importance' of a pattern is the amount of total explained variance.

\section{RESULTS}

\subsection{Annual variability of the beginning of growing season}

As a long-term average (1969-1998) the BGS in Europe starts on 23 April. Since 1989 very early dates have prevailed (Fig. 2). Between 1989 and 1998, 8 out of 10 years tend towards an earlier onset of spring. The earliest date was observed in 1990 (9 April). Because of the long and hard winter in 1995/96, the BGS in 1996 was relatively late. Mainly in SE Europe the leaf unfolding started up to 0.5 mo later in this year (for example, at the IPG in Skopje/Macedonia). The latest date in the period 1969-1998 was registered for 1970 (3 May).

The distinct changes in the average BGS in Europe since 1989 correspond well with changes in the mean air temperature from February to April. Between 1969-1988 and 1989-1998 the mean spring temperature in Europe (T24) increased by $0.8^{\circ} \mathrm{C}$, the average BGS advanced by 8 d (Table 1). The differences between the means both for air temperature and the BGS were significant at $\mathrm{p}<0.05$.
Fig. 2. Deviations of the mean air temperature from February to April (T24) and of the average beginning of growing season (BGS) in Europe, 1969-1998
T24-deviations in ${ }^{\circ} \mathrm{C}$

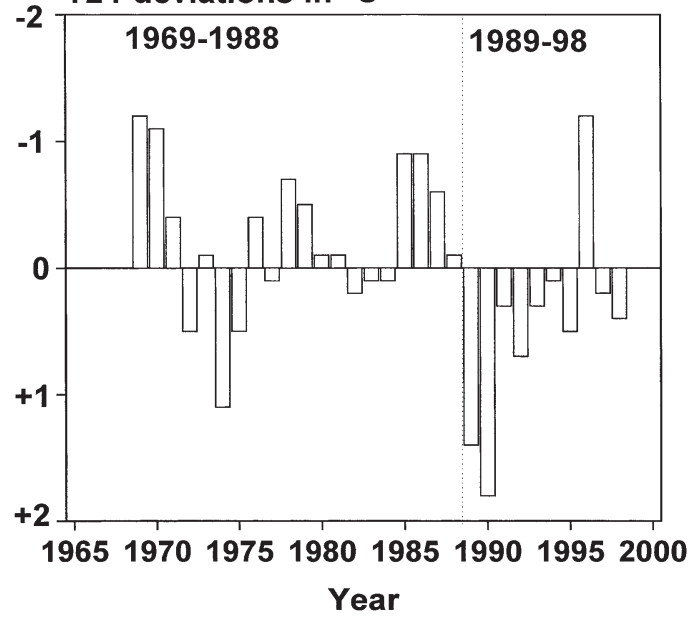

BGS-deviations in days

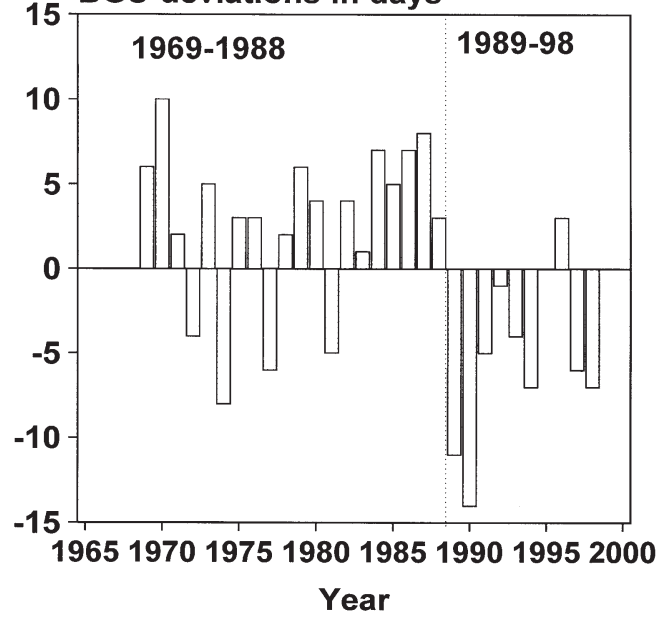




\subsection{Spatial variability of the beginning of growing season}

The BGS showed a distinct spatial variability. Usually, the green wave across Europe moves at $44 \mathrm{~km} \mathrm{~d}^{-1}$ from south to north, at $200 \mathrm{~km} \mathrm{~d}^{-1}$ from west to east and at $32 \mathrm{~m} \mathrm{~d}^{-1}$ with increasing altitude (Rötzer \& Chmielewski 2001). In individual years the spatial distribution of this wave varies to a great extent.

Fig. 3 shows the anomaly patterns of the BGS from 1969 to 1998. Red indicates an advanced beginning of leafing and blue a delayed beginning of leafing in relation to the long-term mean. The changes since 1989 are very impressive. Since this year an advance in the beginning of leafing has clearly prevailed.

In order to investigate the different annual patterns of the BGS across Europe a CCA between the annual pattern of T24 and BGS was calculated. The EOF patterns explain $83 \%$ of the air temperature variability and $72 \%$ of the variance of the BGS in the period 1969-1998.

The first pair of CCA patterns (correlation coefficient: $\mathrm{r}=0.90$ ) shows a relatively homogeneous structure in air temperature and phenology (Fig. 4). Uniform temperature anomalies over the entire area are associated with an early leafing at all IPGs. A mean temperature anomaly for Europe of $\pm 0.6^{\circ} \mathrm{C}$ is related to an advanced or delayed beginning of growing season of $6 \mathrm{~d}$ on average. The strongest anomalies were found in Central Europe. Here positive anomalies of 1.2 to $1.4^{\circ} \mathrm{C}$ in air temperature led to an advanced BGS by 6 to $10 \mathrm{~d}$. In cold years the pattern was opposite, so that leaf unfolding started very late in all regions. This CCA pattern explains $43 \%$ of the variance in the BGS in Europe.

Good examples for the first canonical pair are the years 1970 and 1990 (Fig. 3). In 1970 the BGS in Europe was on average delayed by $10 \mathrm{~d}$. The latest dates were observed in Central and Northern Europe, ranging between +10 and $+20 \mathrm{~d}$. The reverse was observed in 1990, with the earliest date of leaf unfolding between 1969 and 1998. In this year the BGS was $14 \mathrm{~d}$ earlier on average throughout Europe. Anomalies of the BGS in Central Europe, up to -27 d, can be assigned to temperature anomalies from February to April of up to $+4.5^{\circ} \mathrm{C}$.

The second pair of CCA patterns $(r=0.76)$ shows a meridional structure, with warm conditions in the west and cold temperatures in Eastern Europe. According to this temperature pattern, the BGS is early in the western part (on average $-2 \mathrm{~d}$ ) and late in the eastern part $(+2 \mathrm{~d})$ of Europe, so that throughout Europe the vegetation developed normally. This pattern explains $16 \%$ of the variance in phenology.

This meridional structure is clearly discernible in the years 1976 and 1997 (Fig. 3). In 1976 the timing of leaf
Table 1. Mean air temperature from February to April (T24) and average beginning of growing season (BGS) in Europe for 2 different periods: 1969-1988 and 1989-1998. DOY: day of the year. SD: standard deviation

\begin{tabular}{|lllll|}
\hline Period & $\begin{array}{l}\text { T24 } \\
\left({ }^{\circ} \mathrm{C}\right)\end{array}$ & $\begin{array}{c}\text { SD } \\
\left({ }^{\circ} \mathrm{C}\right)\end{array}$ & $\begin{array}{c}\text { BGS } \\
(\mathrm{DOY})\end{array}$ & $\begin{array}{l}\text { SD } \\
(\mathrm{d})\end{array}$ \\
\hline $1969-1988$ & $5.1^{\mathrm{a}}$ & 0.59 & $116^{\mathrm{a}}$ & 4.41 \\
$1989-1998$ & $5.9^{\mathrm{a}}$ & 0.78 & $108^{\mathrm{a}}$ & 5.30 \\
$t$-statistic & a Signif. diff., $\mathrm{p}<0.05$ & \\
\hline \multicolumn{5}{|l}{} \\
\hline
\end{tabular}

unfolding in the northern and eastern parts of Europe was relatively late. In Scandinavia delays between 5 and $8 \mathrm{~d}$ were observed. In addition, in Germany the BGS was on average 1 wk late. Only in SW Germany earlier dates $(-2 \mathrm{~d})$ were observed. The strongest delay (24 d) was recorded at the IPG in Bar/Montenegro. Earlier dates than normal were observed in Western and SW Europe.

While in 1976 striking delays can be found in Eastern and Northern Europe, in 1997 an early BGS was predominant in Western Europe. In this year the BGS advanced by up to $20 \mathrm{~d}$ in the western parts of Europe. The eastern parts of Europe mostly showed delays between 1 and $5 \mathrm{~d}$. Only the IPGs in the Slovak Republic observed delays in leafing of $>10 \mathrm{~d}$.

The third pair of CCA patterns was correlated with $r$ $=0.66$ and explains $14 \%$ of variance. It shows a zonal structure with positive temperature anomalies in the south-mainly SE Europe-and negative anomalies in the north-mainly in Scandinavia. The BGS is delayed by about 3 to $4 \mathrm{~d}$ in the northern latitudes and advanced by up to $5 \mathrm{~d}$ in the southeastern regions.

Good examples for this pattern are the years 1977 and 1981 (Fig. 3). In both years the BGS in Scandinavia was slightly delayed, whereas in Central and Southern Europe early dates prevailed at all IPGs. In 1977 strong deviations from the long-term average were observed, the BGS advanced by up to $-26 \mathrm{~d}$ in SW Germany and Switzerland and by up to $-22 \mathrm{~d}$ in SE Europe.

According to the regional anomalies in the BGS, the individual years can be classified as shown in Table 2.

\section{SUMMARY AND DISCUSSION}

The increase in mean air temperature from February to April of $0.8^{\circ} \mathrm{C}$ over the last decade has led to an earlier BGS in Europe by 8 d. This corresponds well with the results of Walkovszky (1998), who found changes in the flowering dates of the locust tree Robinia pseudoacacia L. in Hungary and related it to the changes in the mean air temperature (period: 15 March to 15 May). Between the periods 1983-1994 

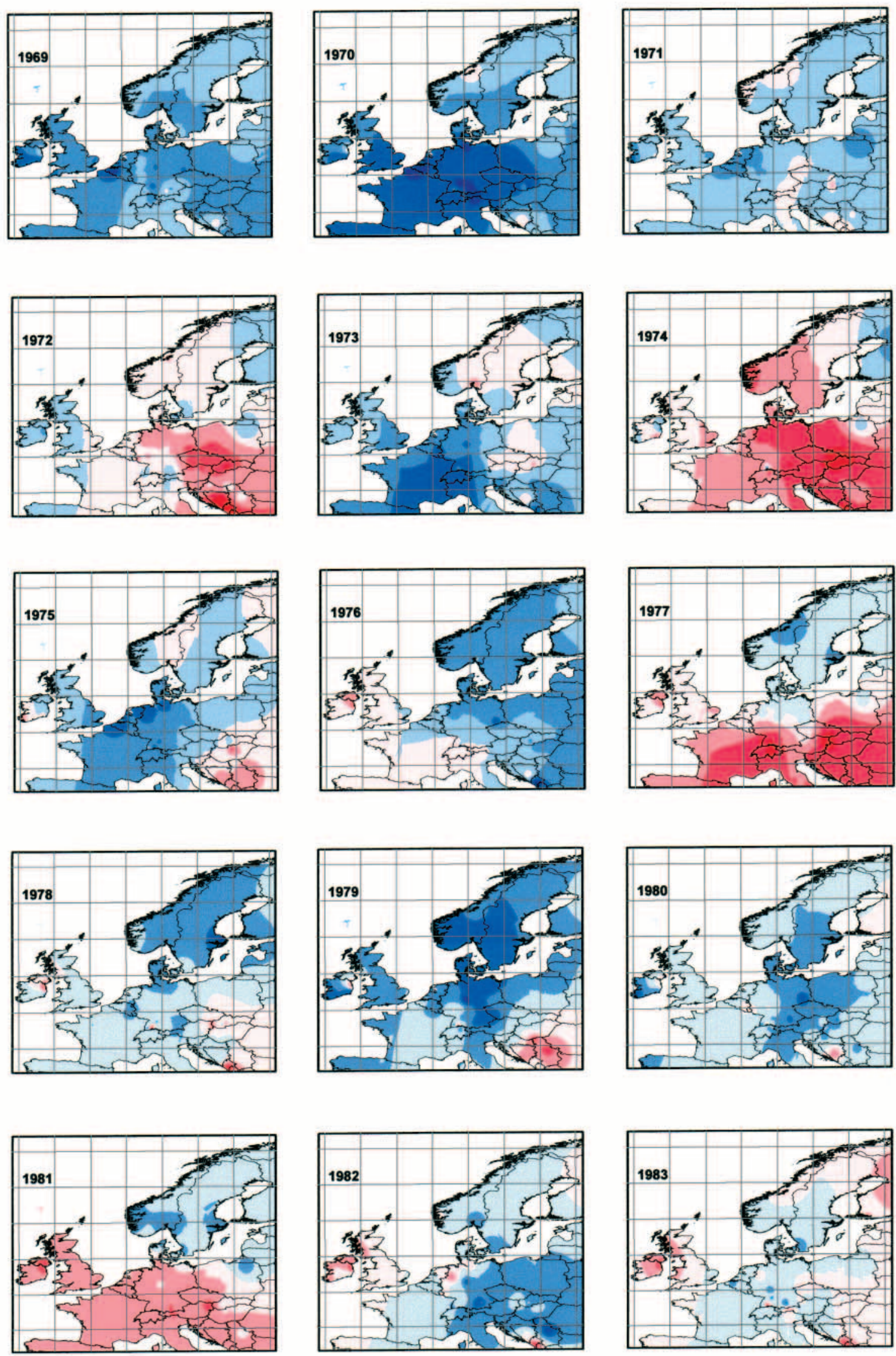

Fig. 3 (this and next page). Regional deviations in the BGS from the long-term average, 1969-1998. Red: advance; blue: delay 

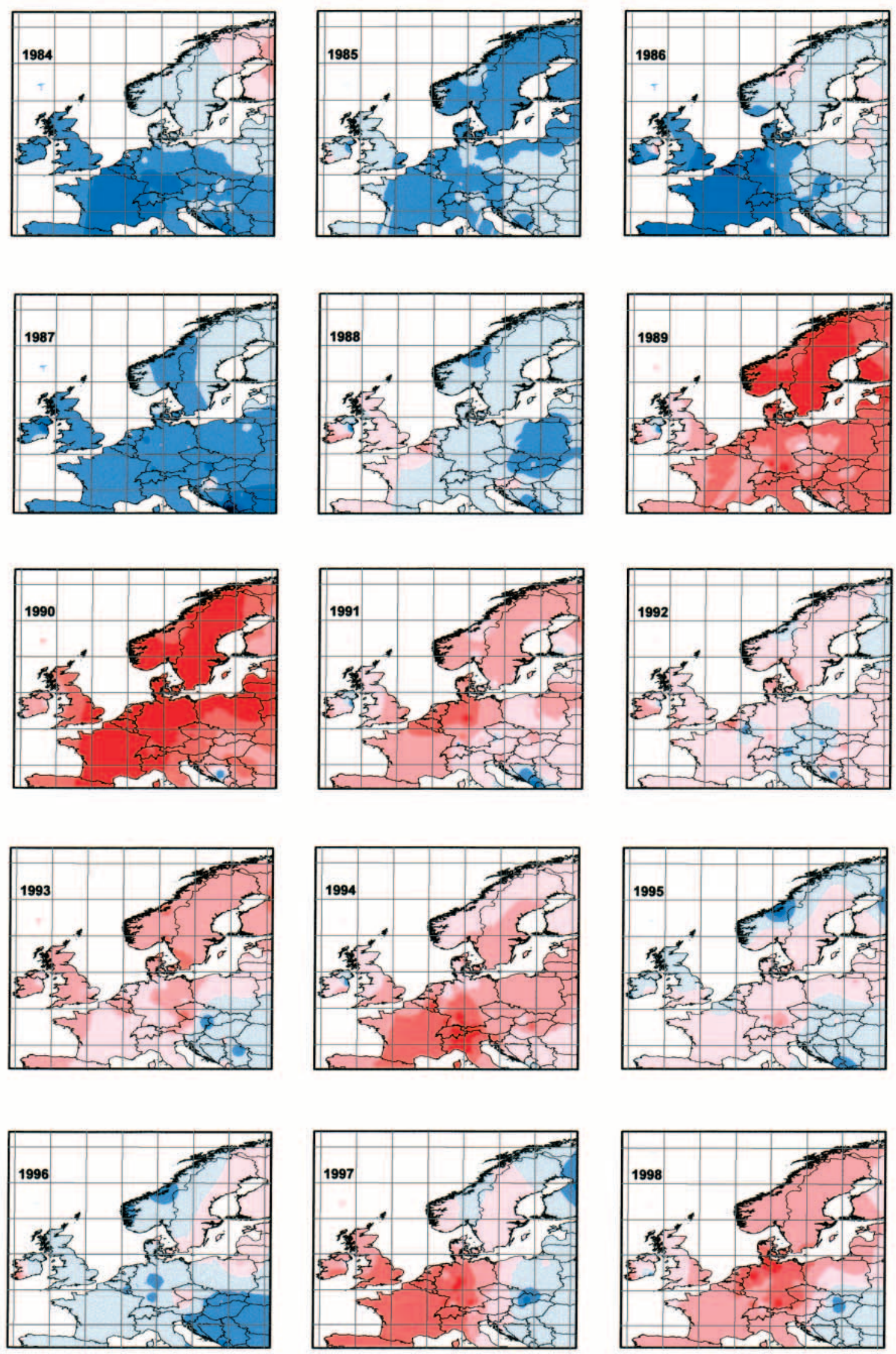

Fig. 3 (continued) 
and 1851-1931 he found an increase in mean air temperature of 0.7 to $1.0^{\circ} \mathrm{C}$, which was in accordance with a shift in the flowering dates of -5 to $-10 \mathrm{~d}$.

In our study primarily the rapid change of the mean air temperature since 1989 and thus the shift in the average BGS in Europe was examined. The changes in air temperature correspond well with changes in the circulation over Europe. Between 1989 and 1998, 10 out of 11 years showed positive phases of the average North Atlantic Oscillation index (NAO: difference in normalized sea-level pressure between Ponta Delgada/Azores and Stykkisholmur, Reykjavik/Iceland) from February to April (Chmielewski \& Rötzer 2001). Positive phases of the NAO in winter and early spring are generally associated with above-normal temperatures in Europe, mainly in the central and northern parts of the continent. The changes found in air temperature are in accordance with the trends analysed by Schönwiese \& Rapp (1997) and Rapp (2000).

The annual spatial variability in the BGS was investigated using CCA. Similar to the results of Maak \& von Storch (1997), CCA reveals a strong relationship between large-scale air temperature from February to April and the BGS in the IPGs across Europe.

As a result of uniform temperature anomalies in Europe in $>40 \%$ of the years, the BGS was either advanced or delayed

Fig. 4. Canonical correlation patterns (CCA1CCA3) of mean monthly air temperature from February to April (T24) and the BGS in Europe, 1969-1998. T24 anomalies are given in ${ }^{\circ} \mathrm{C}$ (red: positive anomalies; blue: negative anomalies) and BGS anomalies in days. The correlation coefficients (r) between the CCA patterns are $\mathrm{r}(\mathrm{CCA} 1)$ $=0.90, \mathrm{r}(\mathrm{CCA} 2)=0.76$ and $\mathrm{r}(\mathrm{CCA} 3)=0.66$
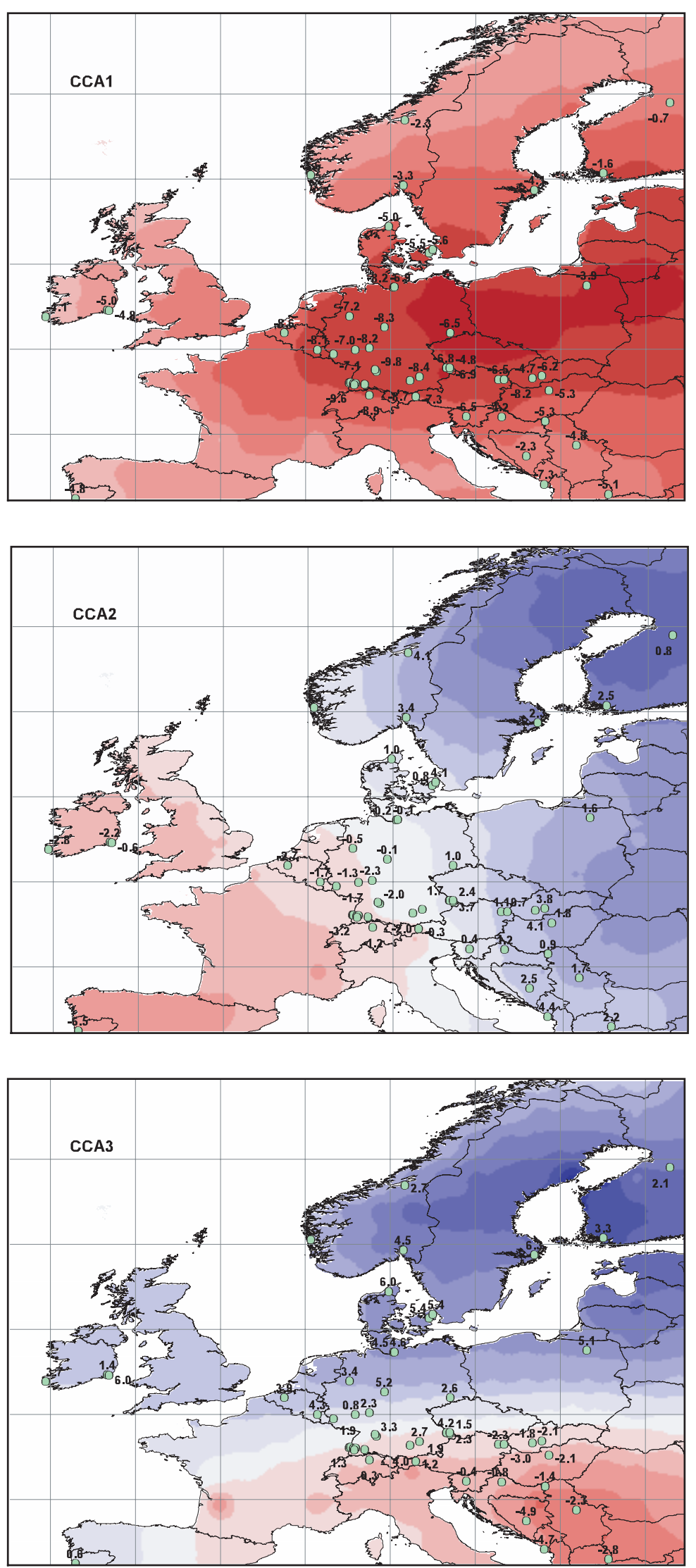
Table 2. Classification of individual years (Fig. 3) to the canonical patterns CCA1, CCA2 and CCA3 (Fig. 4) and average anomalies in the BGS in Europe for these years

\begin{tabular}{|llll|}
\hline Classification & Subgroup & Years & Average BGS anomaly (d) \\
\hline Normal years & & $1992,1983,1995,1971$ & $-2,0,0,+2$ \\
CCA1 pattern & Early years & $1990,1989,1974,1994,1991$ & $-15,-11,-8,-7,-5$ \\
& Late years & $1970,1987,1984,1986,1969,1985,1980,1996$ & $+10,+8,+7,+7,+6,+5,+4,+3$ \\
CCA2 pattern & Meridional differences & $1997,1976,1975,1988$ & $-6,+3,+3,+2$ \\
CCA3 pattern & Zonal differences & 1977,1981 & $-6,-5$ \\
& Only SE-Europe early & 1978,1979 & $+2,+4$, \\
& Only SE-Europe late & 1998,1993 & -4 \\
Undefined years & & $1972,1973,1982$ & $-4,+5,+4$ \\
\hline
\end{tabular}

throughout Europe (CCA1). The 2 other canonical patterns represent unbalanced years, with an early BGS in Western Europe and a late BGS in the eastern part (CCA2) or with earlier dates in Southern Europe (particularly in the southeast) and later dates in Northern Europe (CCA3). The reverse case is always possible. Together these patterns explain another $30 \%$ of variance.

Acknowledgements. The authors thank all observers of the International Phenological Gardens in Europe for the honorable and valuable work over the last 40 years. This study was financially supported by the BMBF in Germany (Project: Climate variability and phenology in Europe, 01LA98501).

\section{LITERATURE CITED}

Beaubien EG, Freeland HJ (2000) Spring phenology trends in Alberta, Canada: links to ocean temperature. Int J Biometeorol 44:53-59

Braslavská O, Kamensky L (1999) Leafing of forest trees and shrubs in the period 1986-1999. Atmosféra Stor Organiz Ekosyst 21:67-71 (in Czech)

Chen X, Tan Z, Schwartz MD, Xu C (2000) Determining the growing season of land vegetation on the basis of plant phenology and satellite data in northern China. Int $\mathrm{J}$ Biometeorol 44:97-101

Chmielewski FM (1996) The International Phenological Gardens across Europe: present state and perspectives. Phenol Seasonal 1:19-23

Chmielewski FM, Rötzer T (2001) Response of tree phenology to climate change across Europe. Agric For Meteorol 108:101-112

Fitter AH, Fitter RSR, Harris ITB, Williamson MH (1995) Relationships between first flowering date and temperature in the flora of a locality in central England. Funct Ecol 9:55-60

Editorial responsibility: Gerd Esser, Gießen, Germany
Hotelling H (1936) Relations between two sets of variants Biometrika 28:321-377

Kalnay E, Kanamitsu M, Kistler R, Collins W and 18 others (1996) The NCEP/NCAR 40-year reanalysis project. Bull Am Meteorol Soc 77:437-471

Maak K, von Storch H (1997) Statistical downscaling of monthly mean air temperature to the beginning of flowering of Galanthus nivalis L. in northern Germany. Int J Biometeorol 41:5-12

Manly BFJ (1986) Multivariate statistical methods, a primer. Chapman \& Hall, London

Menzel A (2000) Trends in phenological phases in Europe between 1951 and 1996. Int J Biometeorol 44:76-81

Rapp J (2000) Konzeption, Problematik und Ergebnisse klimatologischer Trendanalysen für Europa und Deutschland. Ber Dtsch Wetterdienst 212:145S

Rötzer T, Chmielewski FM (2001) Phenological maps of Europe. Clim Res 18:249-257

Schönwiese CD, Rapp J (1997) Climate trend atlas of Europe based on observations 1891-1990. Kluwer Academic, Dordrecht

Schwartz MD (1999) Advancing to full bloom: planning phenological research for the 21st century. Int J Biometeorol 42:113-118

Schwartz MD, Reed BC (1999) Surface phenology and satellite sensor-derived onset of greenness: an initial comparison. Int J Remote Sens 20:3451-3457

Sparks TH, Jeffree EP, Jefree CE (2000) An examination of relationships between flowering times and temperature at the national scale using long-term phenological record from the UK. Int J Biometeorol 44:82-87

von Storch H, Navarra A (eds) (1995) Analysis of climate variability: applications of statistical techniques. SpringerVerlag, Heidelberg

Walkovszky A (1998) Changes in phenology of the locust tree (Robinia pseudoacacia L.) in Hungary. Int J Biometeorol 41:155-160

Wielgolaski FE (1999) Starting dates and basic temperatures in phenological observations of plants. Int J Biometeorol 42:158-168

Submitted: December 4, 2000; Accepted: February 19, 2001 Proofs received from author(s): November 27, 2001 